\title{
Are Only A Few Hours Adequate For Hospitalization Following Mini-Incision Open Appendectomy In Pediatric Patients?
}

\section{Paiboon Sookpotarom}

Panyananthaphikkhu Chonprathan Medical Center, Srinakharinwirot University

\section{Vichack Chakrapan Na Ayudhya}

Panyananthaphikkhu Chonprathan Medical Center, Srinakharinwirot University

Vorapatu Tangsirapat ( $\nabla$ vorapatu@hotmail.com )

Panyananthaphikkhu Chonprathan Medical Center, Srinakharinwirot University

\section{Research Article}

Keywords: appendicitis, appendectomy, short stay, ambulatory, mini-incision

Posted Date: October 7th, 2021

DOI: https://doi.org/10.21203/rs.3.rs-934926/v1

License: (c) (i) This work is licensed under a Creative Commons Attribution 4.0 International License.

Read Full License 


\section{Abstract}

Purpose A very short hospital length of stay following an open appendectomy in children with acute simple appendicitis has never been mentioned yet in literature. The authors reviewed the outcome of these pediatric patients who were treated with the open technique.

Methods -We retrospectively reviewed the medical records of the 115 consecutive patients who underwent open appendectomy from June 2017 to July 2021.

Results- There were 84 patients whose appendices were inflammatory or suppurative and appendectomies were done only through McBurney's point. Of these, the average age was $9.11 \pm 2.67$ years. The mean length of the incision was $1.95 \pm 0.48$ centimeters. Nearly one-third $(25 / 85)$ could be discharged with 3 hours following surgery. Of the remaining cases, 9 patients were discharged within the same day.

Conclusion- There were increased percentages of patients who were eligible for our criteria in each year. The confidence of both parents and the therapeutic team on this concept is of paramount importance affecting a shift of paradigm of this treatment of this very common surgical condition.

\section{Introduction}

Over the last decades, a surgical technique for the treatment of acute non-complicated appendicitis gradually improves with resultant shorter hospitalization. Currently, the same-day discharge or ambulatory setting for treating patients with acute simple appendicitis has been shown feasible in clinical practice [1, 2]. However, up to the present time, short-term inpatient hospitalization has been successfully applied only to adult patients who were treated by laparoscopic technique. Although these efforts have also been tried to implement in children, the patients demonstrated in these publications were still treated by laparoscopic technique $[3,4]$. The concept of the postoperative short stay in pediatric patients with acute simple appendicitis following open appendectomy has never been yet mentioned in the literature.

Recently, we have published a preliminary report of our short-term experience with small incision technique and very short postoperative hospital stay [5]. However, the study had many limitations especially the number of patients. As a result, as the number has increased, we re-evaluate our data expecting that this study will present a more conclusive result.

\section{Methods}

Medical records of pediatric patients with acute simple appendicitis between June 2017 and July 2021 were retrospectively reviewed. The institutional review board (IRB) granted permission with IRB ID EC 016/62. Informed consent from all subjects and/or their legal guardian(s) for participation in this study, to publish the information, and publication of images in an online open access publication was obtained. 
All patients with pathologic confirmation of acute inflammatory or acute suppurative appendicitis were included, whereas the patients whose appendix was necrotizing or perforated were excluded. Mostly, the diagnosis of acute appendicitis was made on three bases including clinical presentations, complete blood count, and urinalysis. Before the surgery, a single dose of 10 milligram/kilogram (mg/kg) metronidazole and $5 \mathrm{mg} / \mathrm{kg}$ gentamicin were given intravenously to all patients.

\section{Surgical techniques}

For the small incision technique, the same as previously described in our publication [6], transverse skin length of 1.5 to 2.5 centimeters $(\mathrm{cm})$ up to the patient's fat thickness, at right lower quadrant (RLQ) is made with scalpel No.15. We only use a scalpel, a Metzenbaum scissor, Zen retractors (or Army retractors in some cases), and mosquito clamps for entering the peritoneum in all cases without electrocautery. On the account of the small opening, the only surgical instruments used to find the cecum or the appendix are non-toothed thumb forceps and Babcock forceps. The technique requires experience skill and sometimes appendix will be grasped blindly. For some instances, the author used a digit to help find the appendix and break any soft adhesion surrounding the appendix.

The appendix is identified and lifted outside. Double ligation with 1-0 or 2-0 silk suture is performed followed by appendectomy with scalpel No.11. The stump is cleaned with pure phenol and $70 \%$ alcohol solution, respectively. Inversion of the stump is not performed. Following the appendectomy, the $4 \times 4$ gauzes are unfolded and rolled longitudinally for swabbing. The peritoneum is closed by the purse-string technique with a 3-0 (or 2-0) polyglactin suture. Diluted lidocaine $(1-2 \mathrm{mg} / \mathrm{kg})$ is injected at sheath and fat. Finally, the subcuticular sutures with 5-0 polyglactin suture complete the operation.

\section{Criteria for discharge}

Following the surgery, all patients were observed and monitored for any postoperative complications for approximately 1 hour in the recovery room and then transferred back to the pediatric ward. At this point, they were evaluated whether they are capable of recovering and able to resume their diet at home. The term "a few hours" in the study is defined as within three hours. The criteria for discharge which was modified from previous publications are as follow $[7,8]$.

1. Clinical improvement

1.1 Vital signs stable for at least 60 min with body temperature less than 38 degrees Celsius

1.2 Reversal of anesthesia

1.3 Mild to moderate pain

1.4 No bleeding or oozing from the wound

1.5 Minimal nausea or vomiting

1.6 Ability to walk to the toilet for voiding (Fig. 1)

2. No difficult event during operation nor prolonged operative time ( $\leq 60 \mathrm{~min}$ ) 
3. The consultation time is daytime (before 7 PM)

4. Agreement from both patient and parents

If the patient's operation was completed at night-time or there was no agreement from the patient or parents, the other criteria will never be considered. All patients were instructed about their diet and adverse symptoms. Contact information (including an appointment) was given before discharge. Only oral paracetamol was given before discharge. The wound with water-proof dressing was left in place until follow-up unless there were any problems, and approximately 2 weeks after discharge, the wound was reevaluated.

Data are expressed as range and mean \pm SD.

\section{Results}

There were 115 appendectomies. Of these, 6 were excluded on account of unusual position of the appendix which also needed additional midline incision (three due to midgut malrotations and one because of fecal impaction), one was an infant with inflamed retrocecal appendix removed through a midline incision, another one was an obese girl with uncertain history, and 25 patients whose appendices were necrotized (3), perforated (20) or normal (2). The remaining 84 patients who underwent open appendectomy were acute inflammatory or suppurative, the demographic data is shown in Table 1 . The mean patients' age was $9.11 \pm 2.67$ years (range 3.1 to 14.1 months). The average length of the incision was $1.95 \pm 0.48 \mathrm{~cm}$ (range 1.2 to $3.5 \mathrm{~cm}$ ). The average depth of cutaneous fat was $2.09 \pm 1.19 \mathrm{~cm}$ (range 0.5 to $5.5 \mathrm{~cm}$ ). There was a correlation between the length of the incision and fat thickness (R2 value $=$ 0.82 and $p$-value $=0.01$ ). The average operative time was $38.7 \pm 18.7$ minutes (range 10 to 110 minutes). 25 patients could be discharged within 3 hours (mean of $1.52 \pm 0.59$ hours and range of 0.55 to 2.5 hours) and 9 patients who were discharged within the same day (mean of $4.5 \pm 1.44$ hours and range of 3.05 to 7 hours). There were increased percentages of patients who were discharged within a few hours each consecutive year (Fig. 2). The data in Table 2. Shown that the factor of age, white blood cell count (WBC), wound length, operative time were not the factors that influence the decision for early discharge. In the remaining 50 patients, the reasons why they could not be discharged on the same day were shown in Table 3. The reasons in order of frequency included surgery completed at night (35), high fever (14), drowsiness (1), severe vomiting (2), severe pain (1), difficulty in operation (12), and no agreement from parents (8).

\section{Discussion}

Acute appendicitis is one of the most common surgical conditions. Improvement in the treatment results in a shortened hospital length of stay. Currently, the basis of ambulatory surgery can be widely applied to patients treated with appendectomy [9-15]. However, the basis is reportedly successful only in patients who were treated with a laparoscopic approach. The success of this basis has never been reported yet in patients whose operation was an open appendectomy. As we have found in our preliminary report [5], a prolonged admission time before surgical consultation and a high percentage of patients presented their 
symptoms and come to the hospital at night largely impact the possibility of ambulatory surgery policy. In addition, with the nature of the disease, a certain appointment to the outpatient office like other elective surgical conditions is nearly impossible. To determine an appropriate policy to shorten the hospitalization duration of the disease, maybe the term "ambulatory surgery" does not work. As a result, at this time, we re-evaluate our increased data with a basis of immediate discharge rather than with the previously used one.

The outcomes demonstrated in the study might be a result of some factors that enhance our patients' recovery. The no usage of electrocautery can reduce tissue damage, and the use of local anesthesia before abdominal wall closure can reduce postoperative pain. The particularly important factor that improves postoperative recovery is the author (P.S)'s small incision technique with which the overall tissue damage can be reduced. The small wound size that comparable to the size generated by the laparoscopic technique might be the explanation why these patients recovered rapidly. In this series, we have a new smallest incision length (Fig. 3). With the author's experience, some obstacles will be presented to other surgeons should this technique is implemented into general practice. Like other surgical skills, a learning curve is required. Some difficult situations such as the retrocecal or subcecal position of the appendix are the conditions in which an author's unique technique will help. Sequential traction sutures approximately $0.5-1 \mathrm{~cm}$ apart retrograde from base to appendiceal tip could deliver such type of appendix pass through the small opening (Fig. 4a and 4b).

At times, we might experience a situation in which the surgeon's digit is needed delving inside to find the appendix, or sometimes for breaking adhesions and freeing the appendix from surrounding structures. If too much effort is used, some cutaneous contusions will indispensably occur (Fig. 5a). Fortunately, this occurrence reduced over time. In addition, perforation which could be found at any time can cause a problematic event especially when accompanied by a fecalith. In at least 2 cases in our experience, while trying to remove the appendix from a small opening cause to break the fecalith which can leave a very small fraction of it, and results in chronic wound infection (Fig. 5b). However, this will be improved with prolonged recovery. Another obstacle would be the pressure from the co-workers surrounding the surgeon. When a difficult operation occurs, the surgeon might be asked to extend the skin incision from the personnel (e.g., assistants, scrub nurses, or anesthetic nurses). For this circumstance, the surgeon must be firm. After we retracted the incision with greater force, additional space of the opening will appear.

Approximately one-third of the patients in the study could meet our criteria. However, if we subgroup the time into the first and the second two-year period we will discover that over half of the patients in the latter period could be discharged immediately. The age, the patient with underlying disease, the WBC count, the wound length, the operative time, and the stage of the appendicitis were not the factors that impact the early discharge. This increased number could be explained by the change in the mind of the parents and the author's team. Over the years, the team gradually accept this concept until they found that not only this will reduce their workload, but also the parents will save their expenses in the hospital. Up to date, all nurses at duty at our in-patient ward will help to clarify the concept of immediate discharge to the parents. The parents' mindset is another difficulty to deal with. As shown in Table 3, the belief that 
admission is needed exists even in health personnel. There are two children in the study whose both mothers are physicians working at the same author's hospital, a two-night stay is required in both cases.

There is a developed trick that significantly helps explain to parents before entering the operating room. With permission, we recorded a short video of a patient walking to the toilet shortly after the operation and used them as an adjunct tool when counseling with the parents. At present day, almost all patients with acute simple appendicitis who are without any surgical difficulty or problems due to anesthesia can successfully be discharged back to their homes for recovery. As we have discussed earlier, the only common hurdle for this concept is the night-time presentation or the time that results in the operation to be completed at night. Although there is a concept of delay and avoiding the operation at night so that the patient can be put into immediate discharge policy $[16,17]$, we think that the patient's time of discharge will be delayed instead of discharging in the morning after the night operation.

Regarding the concern about the parents' feelings or satisfaction. Although we did not construct a form to collect these data as conducted in other studies [18-20], at the time of follow-up, there was no negative feedback from any parent or caregiver. Interestingly, there was a notable case in our study. Since our in-patient ward does not allow for male persons to stay along the night with patients, so the patient and his lone father were quite happy to go back home for recovery following an hour after surgery.

\section{Conclusion}

According to our results, the concept of immediate discharge seems to be possible for children with acute simple appendicitis who were treated with open appendectomy. In addition to the factors and the author's technique mentioned in the study that might explain the reasons responsible for the results, the confidence of both parents and therapeutic team on this concept is of paramount importance affecting the change or a shift of paradigm concerning the treatment of this very common surgical condition. Another purpose of the study is to propose our unique surgical technique so that the other surgeons can perform as fluently as we do. We expect that the practice is widely accepted and distributed so the parents would save their expense in the hospital as well as many resources would be reduced.

\section{Declarations}

\section{ACKNOWLEDGEMENTS}

We deeply thank Dr.Paisarn Vejchapipat, MD, Ph.D., for some precious comments in this study. There is no funding for this work.

\section{AUTHOR CONTRIBUTIONS}

All authors contributed to the study conception and design. Material preparation, data collection and analysis were performed by P.S., V.C., and V.T. The first draft of the manuscript was written by P.S. and all 
authors commented on previous versions of the manuscript. All authors read and approved the final manuscript.

\section{FUNDING}

The authors did not receive support from any organization for the submitted work.

\section{COMPETING INTERESTS}

The authors declare no competing interests.

\section{ETHICS APPROVAL}

This retrospective chart review study involving human participants was in accordance with the ethical standards of the institutional and national research committee and with the 1964 Helsinki Declaration and its later amendments or comparable ethical standards. The Human Investigation Committee (IRB) of Panyananthaphikkhu Chonprathan Medical Center, Srinakharinwirot University approved this study with IRB ID EC 016/62.

\section{References}

1. Cash, C. L. et al. A prospective treatment protocol for outpatient laparoscopic appendectomy for acute appendicitis. J Am Coll Surg, 215, 101-105 (2012).

2. Sabbagh, C. et al. The feasibility of short-stay laparoscopic appendectomy for acute appendicitis: a prospective cohort study. Surg Endosc, 26, 2630-2638 (2012).

3. Ali, R., Anwar, M. \& Akhtar, J. Laparoscopic versus open appendectomy in children: a randomized controlled trial from a developing country. J Pediatr Surg, 53, 247-249 (2018).

4. Ikeda, H. et al. Laparoscopic versus open appendectomy in children with uncomplicated and complicated appendicitis. J Pediatr Surg, 39, 1680-1685 (2004).

5. Sookpotarom, P., Chakrapan, N. \& Ayudhya, K. Does ambulatory surgery work for open appendectomy?: A review of paediatric cases with simple appendicitis treated in a single institution. Songklanakarin J Sci Technol. Preprint at http://rdo.psu.ac.th/sjstweb/Ar-Press/2020Nov/21.pdf (2020).

6. Sookpotarom, P., Khampiwmar, W. \& Termwattanaphakdee, T. Vigorous wound irrigation followed by subcuticular skin closure in children with perforated appendicitis. J Med Assoc Thai, 93, 318-323 (2010).

7. Hussain, A., Singh, S., Singh Ahi, K. \& Singh, M. Status of Day Care Laparoscopic Appendectomy in Developing Countries. Int Sch Res Notices. 2014, 502786 (2014).

8. Scott, A. et al. Same-Day Discharge in Laparoscopic Acute Non-Perforated Appendectomy. J Am Coll Surg, 224, 43-48 (2017). 
9. Genser, L. \& Vons, C. Can abdominal surgical emergencies be treated in an ambulatory setting? J Visc Surg. 152(6 Suppl), S81-S89(2015).

10. Lefrancois, M. et al. Management of Acute Appendicitis in Ambulatory Surgery: Is It Possible? How to Select Patients? Ann Surg, 261 (6), 1167-1172 (2015).

11. Cosse, C., Sabbagh, C., Grelpois, G., Brehant, O. \& Regimbeau, J. M. Day case appendectomy in adults: a review. Int $J$ Surg, 12, 640-644 (2014).

12. Dubois, L., Vogt, K. N., Davies, W. \& Schlachta, C. M. Impact of an outpatient appendectomy protocol on clinical outcomes and cost: a case-control study. J Am Coll Surg, 211, 731-737 (2010).

13. Akkoyun, I. Outpatient laparoscopic appendectomy in children: a single center experience with 92 cases. Surg Laparosc Endosc Percutan Tech, 23, 49-50 (2013).

14. Gignoux, B. et al. Should ambulatory appendectomy become the standard treatment for acute appendicitis? World J Emerg Surg, 13, 28 (2018).

15. Trejo-Avila, M., Cárdenas-Lailson, E., Valenzuela-Salazar, C., Herrera-Esquivel, J. \& Moreno-Portillo, M. Ambulatory versus conventional laparoscopic appendectomy: a systematic review and metaanalysis. Int J Colorectal Dis, 34, 1359-1368 (2019).

16. Serres, S. K. et al. Time to Appendectomy and Risk of Complicated Appendicitis and Adverse Outcomes in Children. JAMA Pediatr, 171, 740-746 (2017).

17. Cameron, D. B. et al. Time to appendectomy for acute appendicitis: A systematic review. J Pediatr Surg, 53, 396-405 (2018).

18. Ali, R., Anwar, M. \& Akhtar, J. Laparoscopic versus open appendectomy in children: a randomized controlled trial from a developing country. J Pediatr Surg, 53, 247-249 (2018).

19. Anderson, K. A., Abernathy, S. W., Jupiter, D. \& Frazee, R. C. Patient Satisfaction After Outpatient Appendectomy. J Laparoendosc Adv Surg Tech A, 26, 954-957 (2016).

20. Alkhoury, F. et al. A prospective study of safety and satisfaction with same-day discharge after laparoscopic appendectomy for acute appendicitis. J Pediatr Surg, 47, 313-316 (2012).

\section{Tables}


Table 1

Demographic data

\begin{tabular}{|lll|}
\hline & N or Mean \pm SD & \% or Range \\
\hline Age (year) & $9.11 \pm 2.67$ & $3.06-14.11$ \\
\hline Sex (Male) & 71 & $49.30 \%$ \\
\hline Body mass index & $18.15 \pm 4.3$ & $11.8-34.6$ \\
\hline Underlying disease & 7 & $8.30 \%$ \\
\hline Allergy & 1 & $1.20 \%$ \\
\hline Body temperature $\left({ }^{\circ} \mathrm{C}\right)$ & $37.5 \pm 0.9$ & $36-40.7$ \\
\hline White blood cell count $\left(x 10^{3}\right)$ & $15.82 \pm 7.11$ & $5.34-49.42$ \\
\hline Neutrophil (\%) & $78.87 \pm 10.88$ & $45-94.1$ \\
\hline Fat thickness (cm) & $2.09 \pm 1.19$ & $0.5-5.5$ \\
\hline Wound length (cm) & $1.95 \pm 0.48$ & $1.2-3.5$ \\
\hline Operative time (minutes) & $38.68 \pm 18.75$ & $10-110$ \\
\hline Time to discharge (Hours) & $9.46 \pm 8.25$ & $0.55-52.3$ \\
\hline Stage & & \\
\hline Inflamed appendicitis & 57 & $67.90 \%$ \\
\hline Suppurative appendicitis & 27 & $32.10 \%$ \\
\hline Discharge within 3 hours & 25 & $29.80 \%$ \\
\hline
\end{tabular}


Table 2

Compare between patients who can discharge within 3 hours after the operation, and patients who can discharge more than 3 hours after the operation

\begin{tabular}{|c|c|c|c|c|c|}
\hline & \multicolumn{2}{|l|}{$\leq$ 3hours } & \multicolumn{2}{|l|}{$>3$ hours } & \multirow{2}{*}{$\begin{array}{l}\mathrm{P} \text { - } \\
\text { value }\end{array}$} \\
\hline & $\begin{array}{l}\text { Nor } \\
\text { Mean } \pm S D\end{array}$ & $\begin{array}{l}\% \text { or } \\
\text { Range }\end{array}$ & $\begin{array}{l}\text { Nor } \\
\text { Mean } \pm S D\end{array}$ & $\begin{array}{l}\% \text { or } \\
\text { Range }\end{array}$ & \\
\hline Age & $8.82 \pm 2.51$ & $4.06-14.08$ & $9.24 \pm 2.75$ & $3.06-14.11$ & 0.5 \\
\hline Sex (Male) & 14 & $56 \%$ & 28 & $47.50 \%$ & 0.47 \\
\hline Body mass index & $18.97 \pm 3.75$ & 13.9-26.6 & $17.81 \pm 4.49$ & $11.8-34.6$ & 0.54 \\
\hline Underlying & 4 & $16 \%$ & 3 & $5.1 \%$ & 0.1 \\
\hline Allergy & 0 & 0 & 1 & $1.7 \%$ & 0.51 \\
\hline Body temperature $\left({ }^{\circ} \mathrm{C}\right)$ & $37.4 \pm 0.7$ & $36-39$ & $37.6 \pm 1 \%$ & $36-40.7$ & 0.41 \\
\hline $\begin{array}{l}\text { White blood cell count } \\
\left(x 10^{3}\right)\end{array}$ & $16.35 \pm 8.36$ & $7.24-49.4$ & $15.59 \pm 6.58$ & $5.34-47.6$ & 0.27 \\
\hline Neutrophil (\%) & $76.2 \pm 10.5$ & 48.9-90.6 & $80 \pm 10.9$ & $45-94.1$ & 0.18 \\
\hline Fat thickness (cm) & $2.2 \pm 1.22$ & $0.5-5.5$ & $2.04 \pm 1.19$ & $0.5-5$ & 0.21 \\
\hline Wound length (cm) & $1.98 \pm 0.48$ & $1.2-2.8$ & $1.94 \pm 0.49$ & $1.3-3.5$ & 0.21 \\
\hline Operative time (minutes) & $33.8 \pm 1.14$ & $20-65$ & $40.75 \pm 2.08$ & $10-110$ & 0.74 \\
\hline Stage & & & & & 0.12 \\
\hline Inflamed appendicitis & 20 & $80 \%$ & 37 & $62.7 \%$ & \\
\hline Suppurative appendicitis & 5 & $20 \%$ & 22 & $37.3 \%$ & \\
\hline
\end{tabular}

Table 3

The reasons why the patients needed over-night hospital stay

\begin{tabular}{|lllllll|}
\hline $\begin{array}{l}\text { Nighttime or } \\
\text { raining }\end{array}$ & $\begin{array}{l}\text { High } \\
\text { fever }\end{array}$ & Drowsiness & $\begin{array}{l}\text { Severe } \\
\text { vomiting }\end{array}$ & $\begin{array}{l}\text { Severe } \\
\text { pain }\end{array}$ & $\begin{array}{l}\text { Difficult } \\
\text { operation }\end{array}$ & $\begin{array}{l}\text { No } \\
\text { agreement }\end{array}$ \\
\hline 35 & 14 & 1 & 2 & 1 & 12 & 8 \\
\hline
\end{tabular}

\section{Figures}




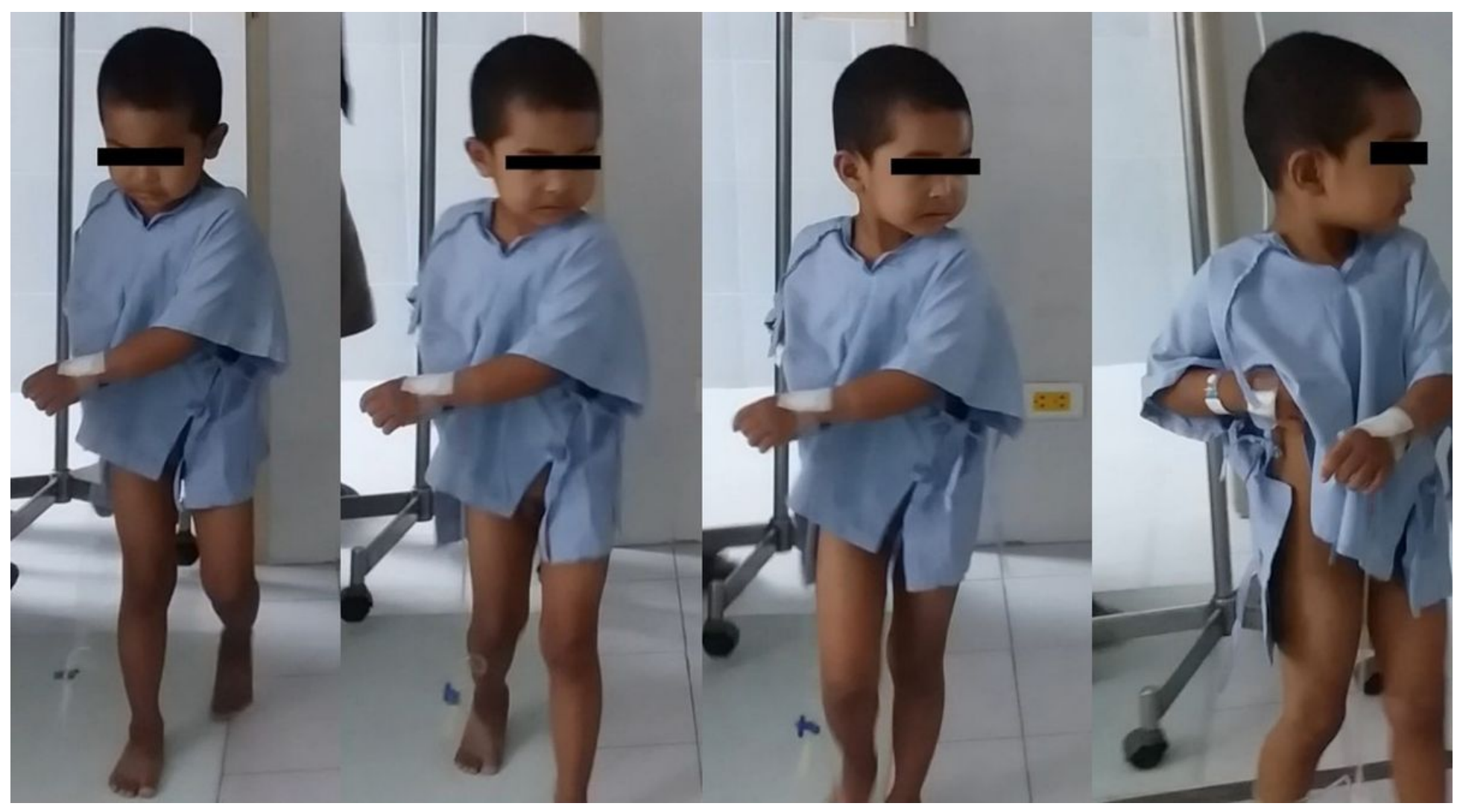

Figure 1

Screenshot capture of a video recorded showing an ability in a 4-year-old boy to walk to void approximately 90 min following surgery 


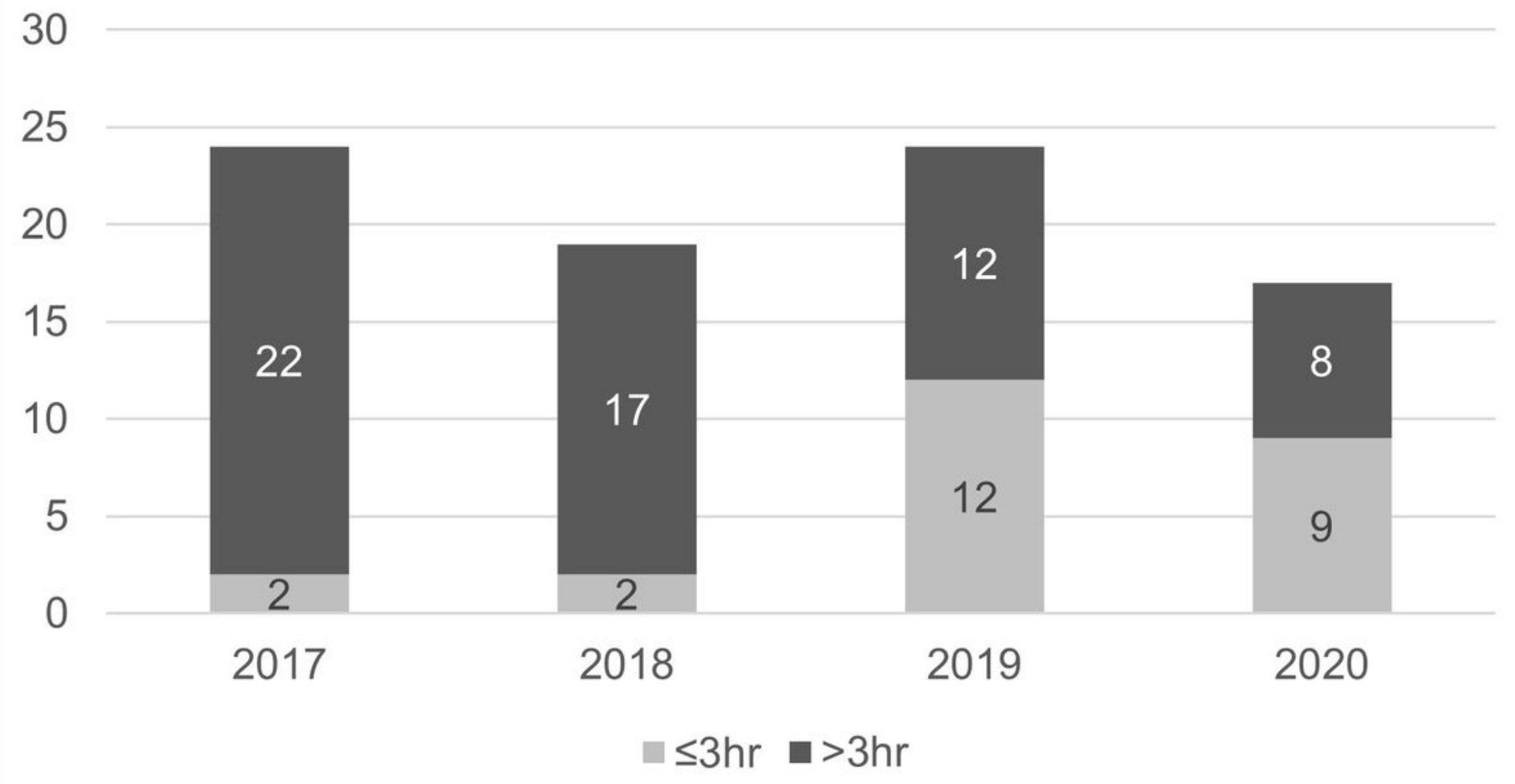

Figure 2

Showing percentage of patients who were eligible for our criteria in each year

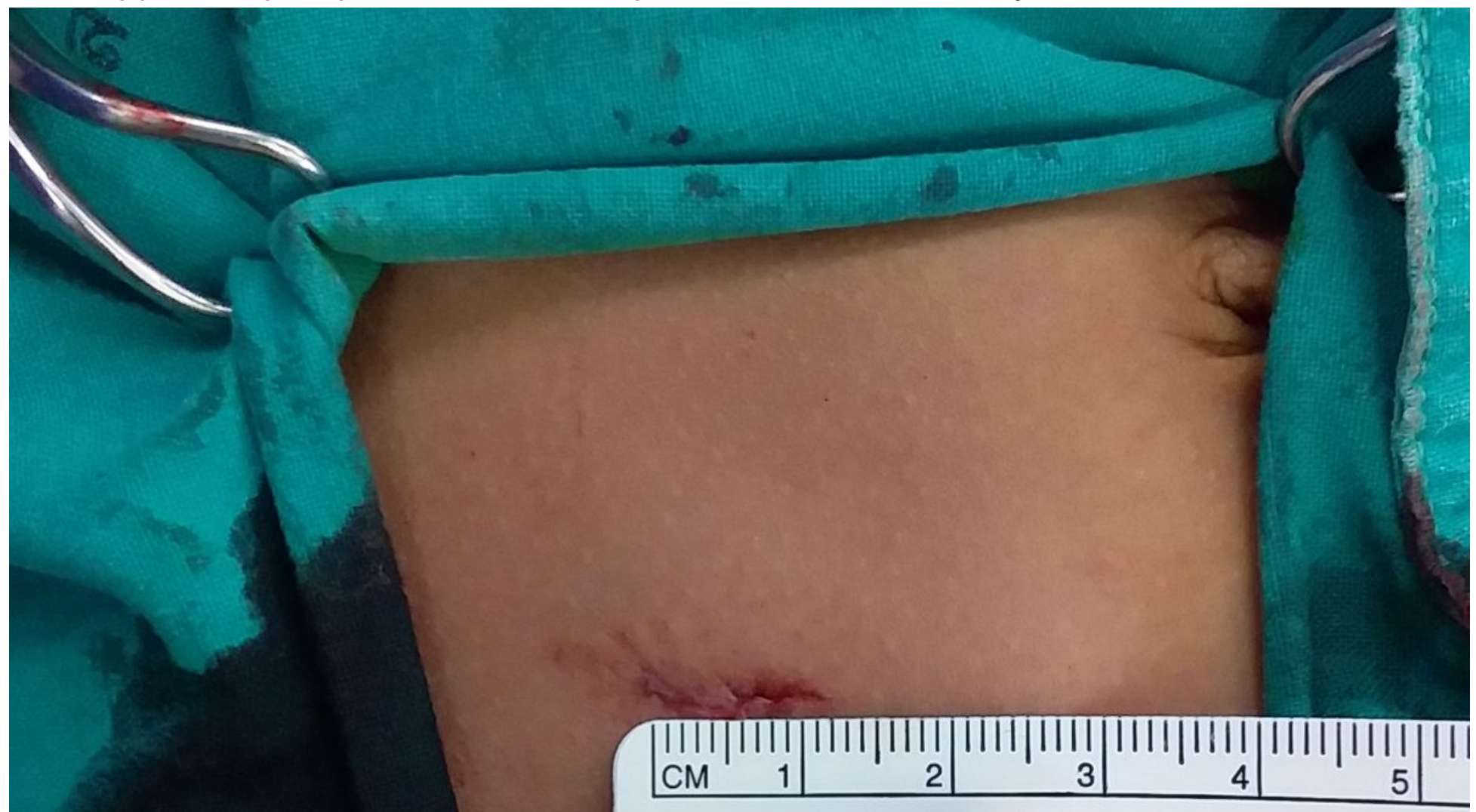


Figure 3

The smallest length of incision in the study

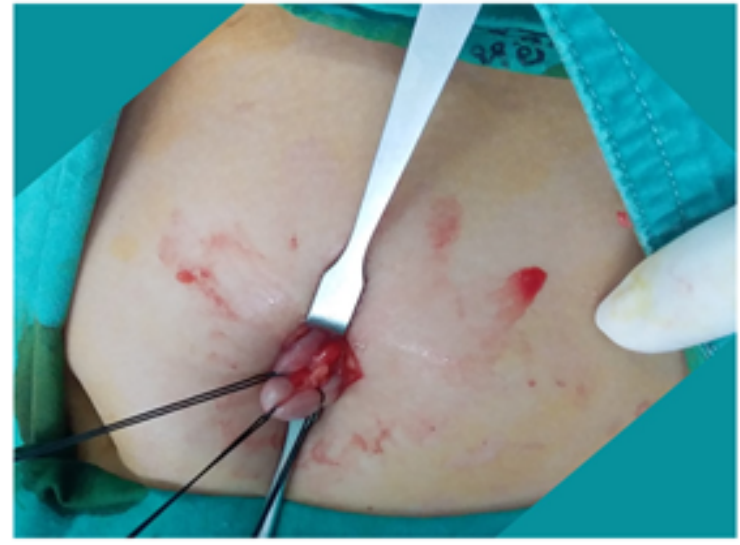

Fig 4a

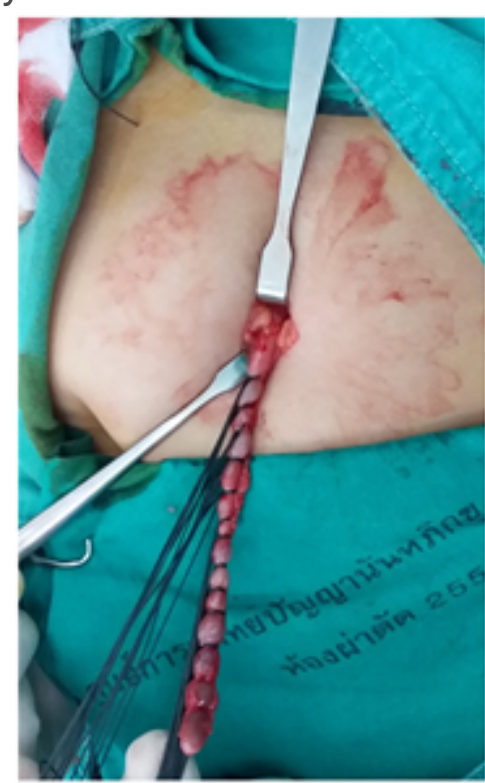

Fig $4 \mathrm{~b}$

\section{Figure 4}

4a and 4b Sequential traction sutures were applied in a patient with appendicitis, retrocecal type

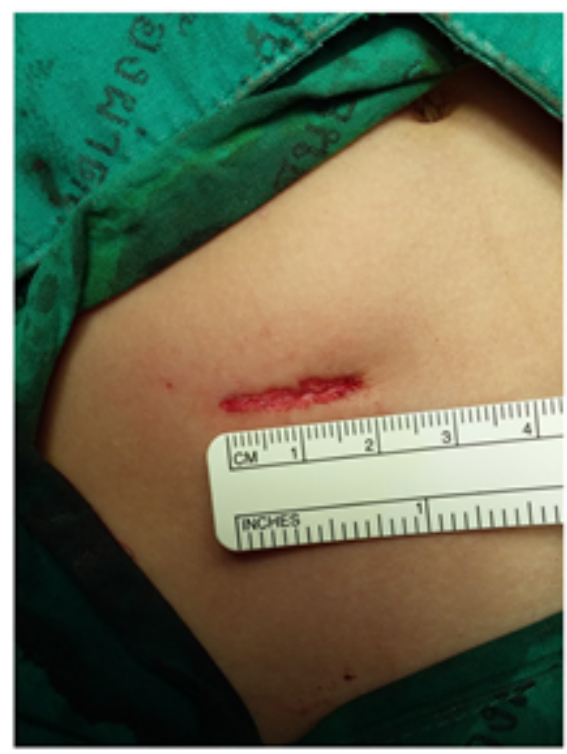

Fig 5 a

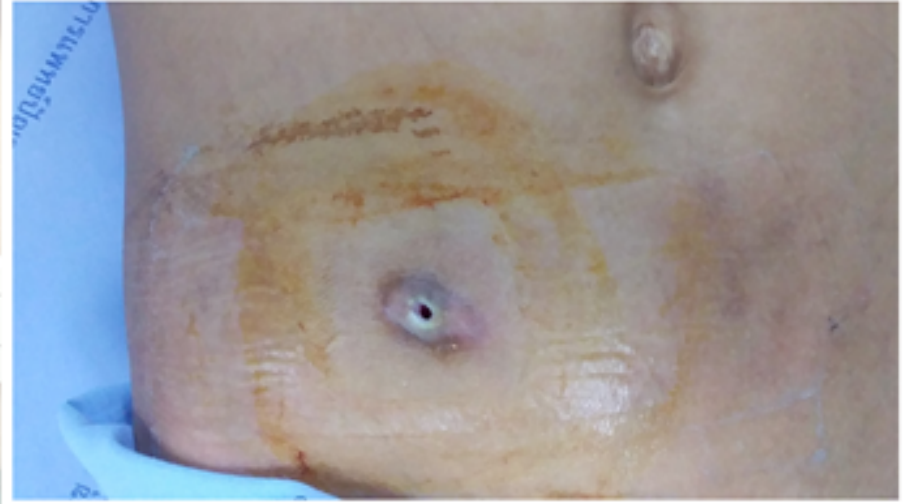

Fig $5 b$

\section{Figure 5}

5a Contusion at the edge of both sides of incision presented following a procedure with which too much effort is required Fig. $5 b$ The presence of chronic wound infection in a patient who was suspected of having a retention of fecalith. 